\title{
Recommended changes for the 8th edition of the TNM classification for lung cancer-the findings of a single-institution evaluation
}

\author{
Jia Wang, Nan Wu, Chao Lv, Shi Yan, Yue Yang \\ Key Laboratory of Carcinogenesis and Translational Research (Ministry of Education/Beijing), Department of Thoracic Surgery II, Peking \\ University Cancer Hospital \& Institute, Beijing 100142, China \\ Contributions: (I) Conception and design: J Wang, Y Yang; (II) Administrative support: N Wu; (III) Provision of study materials or patients: J Wang, \\ C Lv; (IV) Collection and assembly of data: J Wang, S Yan; (V) Data analysis and interpretation: J Wang; (VI) Manuscript writing: All authors; (VII) \\ Final approval of manuscript: All authors. \\ Correspondence to: Yue Yang, MD. Department of Thoracic Surgery II, Peking University School of Oncology, Beijing Cancer Hospital \& Institute., \\ No. 52, Fucheng Avenue, Haidian District, Beijing 100142, China. Email: zlyangyue@bjmu.edu.cn.
}

Background: To evaluate the efficacy of the nodal descriptors and subgroups proposed by International
Association for the Study of Lung Cancer (IASLC) in the 8th edition of the TNM classification system and
to provide references for future editions. Methods: A total of 3,177 patients with non-small cell lung cancer at the Beijing Cancer Hospital were classified based on the following three methods: (I) the $\mathrm{N}$ descriptors in the 8th edition of the TNM classification system: N0, N1, N2, and N3; (II) the IASLC-proposed N subgroups: N1a, N1b, N2a1, N2a2, and N2b; (III) our more extensive division method: N1a, N1b, N1c, N2a1, N2a2, N2b1, N2b2, N2c, N3a, and N3b. Five-year survival analysis was performed using the Kaplan-Meier method, and differences between subgroups were evaluated using the log-rank test.

Results: (I) A significant survival difference was found between each adjacent $\mathrm{N}$ descriptor; (II) the difference between each adjacent subgroup $\mathrm{N}$ descriptor was significant, but the difference between $\mathrm{N} 1 \mathrm{~b}$ and N2a1 was not; (III) in our proposed method, a significant difference was found between all the subgroups apart from N2a2 and N2b1, N2b1 and N2b2, N2c and N3a, and N3a and N3b.

Conclusions: The $\mathrm{N}$ descriptors in the 8th edition of the tumor, node, and metastasis (TNM) classification system are consistent with our data. Although our more extensive division method could distinguish between patients at different stages, its implementation is complicated; thus, we recommend the implementation of the IASLC-proposed subgroups with the addition of the N1b and N2a1 groups.

Keywords: N descriptor; non-small lung cancer; International Association for the Study of Lung Cancer (IASLC); 8th edition tumor, node, and metastasis (8th edition TNM)

Submitted Dec 30, 2019. Accepted for publication Jan 04, 2020.

doi: $10.21037 /$ atm.2020.01.129

View this article at: http://dx.doi.org/10.21037/atm.2020.01.129

\section{Introduction}

Globally, lung cancer is the most common form of malignant tumor and is also the leading cause of cancerrelated deaths (1). The accurate categorization of tumor stage, including lymph node status, is therefore crucial for prognostic assessment, as well as for determining a stage- specific therapeutic strategy for lung cancer patients (2). The internationally accepted standard for cancer staging is the tumor, node, and metastasis (TNM) classification system, which has been published by the Union for International Cancer Control (UICC) for more than 50 years $(3,4)$. The lung cancer classification method for the TNM staging 
system was conducted by the International Association for the Study of Lung Cancer (IASLC) (5-7). Although the staging of lung cancer must maintain consistency in relation to nomenclature, revisions are needed as technology, which extends the ability to define tumor progresses, develops and improves. Therefore, the classification system is periodically updated by the UICC, and the latest $\left(8^{\text {th }}\right)$ edition was implemented in January 2018 (8-10).

The $\mathrm{N}$ descriptors described in the $7^{\text {th }}$ edition of TNM for lung cancer separated patients into different groups consistently, and these remain unchanged in the $8^{\text {th }}$ edition (Table 1) (11). The $\mathrm{N}$ descriptors are based only on nodal location, and to give a more accurate prognosis, the IASLC proposed more refined $\mathrm{N}$ subgroups which subdivide $\mathrm{N}$ descriptors according to a combination of the location of metastatic nodes and the absence versus the presence of skip metastasis. These subgroups are N0, N1a (N1 single station), N1b (N1 multiple station), N2a1 (N2 single with skip metastasis), N2a2 (N2 single without skip metastasis), and N2b (N2 multiple station) (Table 1).

This classification system was based on a comprehensive statistical analysis of an international database comprising 94,708 lung cancer patients diagnosed between 1999 and 2010. Of these, data were available from 38,910 patients with non-small cell lung carcinoma (NSCLC) for the analysis of the clinical $\mathrm{N}$ status (5). Despite lung cancer being the most common cause of mortality in China $(1,12)$, less than one percent $(790$ of 94,708$)$ of data used in the development the 8th edition of the TNM classification was from patients in China (5). Furthermore, studies aimed at validating the new staging system focusing on the $\mathrm{N}$ descriptor in the Chinese population have been poor (13-15), and as such, further investigation into the prognostic ability of this new classification in China is required.

In this study, we performed a single-institution evaluation of the efficacy and the validity of the $8^{\text {th }}$ edition $\mathrm{N}$ classification for the prognostic assessment of NSCLC patients who received surgical therapy. Moreover, to explore if there is a more sophisticated method for describing the tumor burden in lymph nodes, we further refined the IASLC $\mathrm{N}$ categories into more detailed subgroups. As shown in Table 1: N1 was divided into N1a, N1b, and N1c (all N1 station); N2 was subclassified into N2a1, N2a2, N2b1 (multiple N2 stations with skip metastasis, without N1 metastasis), N2b2 (multiple N2 stations with N1 metastasis, without skip metastasis), and N2c (all N1 and $\mathrm{N} 2$ stations); and $\mathrm{N} 3$ was separated into $\mathrm{N} 3$ a (single N3 station with skip metastasis, without $\mathrm{N} 1$ and $\mathrm{N} 2$ metastasis) and $\mathrm{N} 3 \mathrm{~b}$ (single or multiple $\mathrm{N} 3$ station with $\mathrm{N} 1$ and $\mathrm{N} 2$ metastasis, without skip metastasis).

In summary, the aims of this study were to evaluate whether the $\mathrm{N}$ descriptors in the $8^{\text {th }}$ edition were effective in categorizing lung cancer patients in China and to compare whether our subgroup strategy can offer a more refined version of the $\mathrm{N}$ classification system than the $8^{\text {th }}$ edition, while providing a point of reference for revisions of future editions.

\section{Methods}

\section{Patients}

A total of 3,177 patients who were diagnosed with stages I to IV of non-small cell lung cancer (NSCLC) at the Thoracic Surgery Department II (Beijing Cancer Hospital, Beijing, China) between October 2003 and August 2017 were included in this study. These patients received resections for tumors with mediastinal lymph node dissection or systematic lymph node sampling. This retrospective study was approved by the Institutional Review Board of Peking University Cancer Hospital, and the requirement for patients' consent was waived.

\section{Collection of clinical data}

In our study, all of the subjects had pathologic data of lymph nodes. Pulmonary function testing and cardiac evaluation were required as preoperative assessments. To evaluate the preoperative extent of the disease, brain magnetic resonance imaging (MRI) or computed tomography (CT), bone scintigraphy, and abdominal and supraclavicular ultrasound scanning were routinely performed. Positron emission tomography (PET)/CT scans were not routinely used due to concerns surrounding expense. Postoperatively, patients were examined generally every three months for the first two years and every six months for the next three years, and then every year thereafter. Recurrence and survival rates were examined during each follow up. The median followup period was 72 (ranging from 1 to 190) months. The data of surviving patients were censored at the date of the last follow up.

\section{Statistical analysis}

All patients were staged using the methods listed in Tables 1 and 2. The Kaplan-Meier method was used to perform 
Table 1 Definitions of nodal classification methods

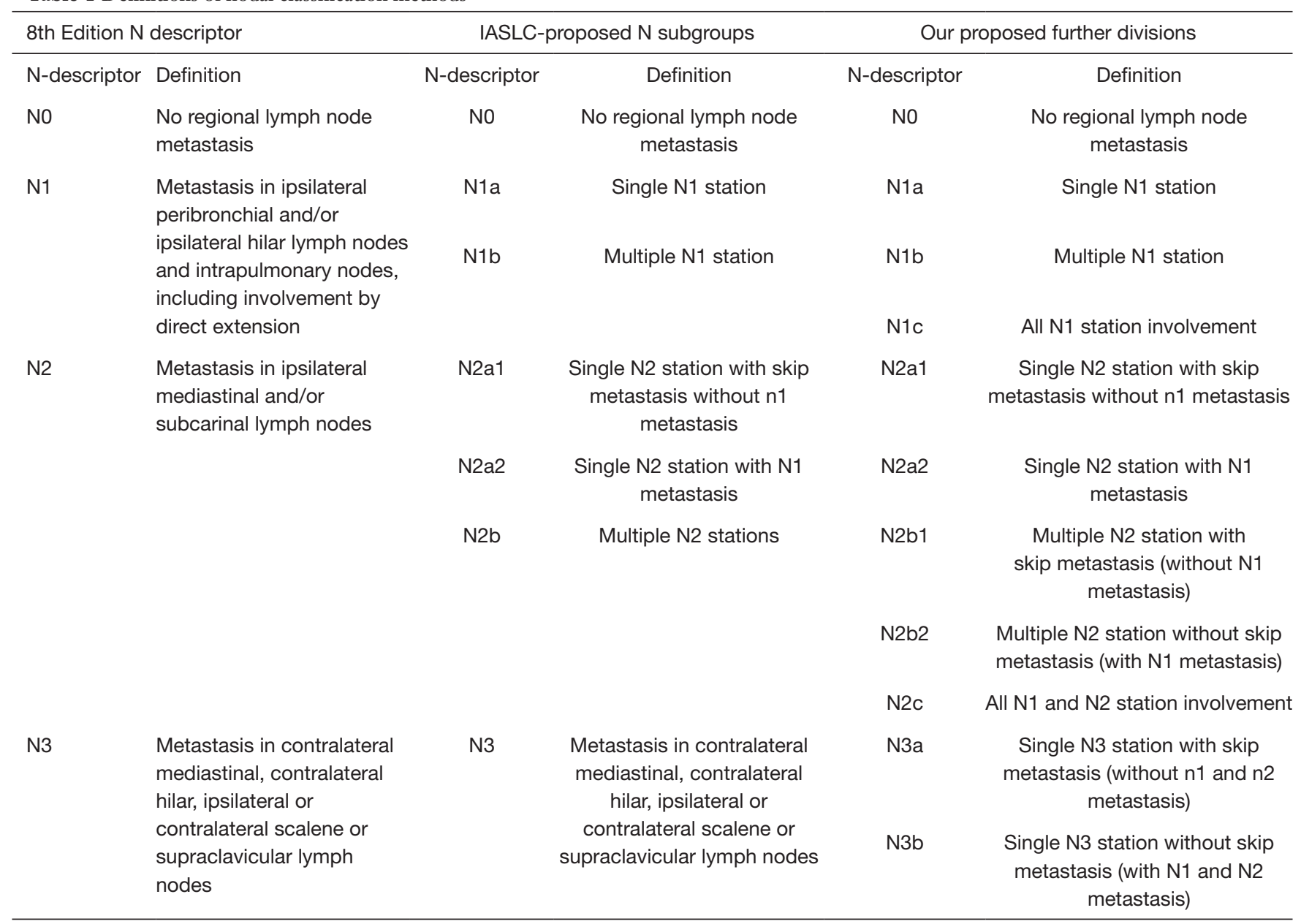

five-year survival analysis, and the log-rank test was used to evaluate differences between sub-groups. All standard statistical procedures were performed using SPSS (version 20.0; IBM, Chicago, IL, USA). The difference between groups was considered significant when $\mathrm{P}$ value $<0.05$.

\section{Results}

\section{Patient demographics and characteristics}

A total of 3,177 patients were included in this study, and Table 2 lists their demographics and characteristics. The median age was 62 (range, 24-84) years. There were $1,760(55.4 \%)$ male and 1,417 (44.6\%) female patients. Of the patients, 2,557 (80.5\%) had adenocarcinoma, $416(13.1 \%)$ had squamous cell carcinoma, 89 (2.8\%) had adenosquamous carcinoma, 60 (1.9\%) had large-cell carcinoma, and 55 (1.7\%) had other types of lung cancer. Of the patients in our study, 2,343 (73.7\%) patients underwent lobectomy, 422 (13.3\%) patients underwent segmentectomy, $128(4.0 \%)$ patients underwent bilobectomy, $113(3.5 \%)$ patients underwent pneumonectomy, $98(3.1 \%)$ patients underwent wedge resection, and $65(2.0 \%)$ patients underwent exploratory thoracotomy. A total of 967 (30.4\%) patients received perioperative therapy, 294 (9.3\%) patients received neo-adjuvant chemotherapy, 277 (8.7\%) patients underwent neo-adjuvant targeted therapy, and 729 (22.9\%) and $312(9.8 \%)$ patients at stage IB or higher underwent adjuvant chemotherapy or adjuvant target therapy, respectively. Postoperative radiotherapy was administered to 467 (14.7\%) patients.

\section{Patient stratifications}

Table 3 shows patients classified into the $\mathrm{N}$-descriptor stages 
Table 2 Patients' demographics and characteristics $(\mathrm{n}=3,177)$

\begin{tabular}{|c|c|c|}
\hline Characteristics $(\mathrm{N}=3,611)$ & Records & Percentage (\%) \\
\hline \multicolumn{3}{|l|}{ Gender } \\
\hline Male & 1,760 & 55.4 \\
\hline Female & 1,417 & 44.6 \\
\hline Age [range] & 62 [24-84] & \\
\hline \multicolumn{3}{|l|}{ Surgical procedure } \\
\hline Lobectomy & 2,343 & 73.7 \\
\hline Segmentectomy & 422 & 13.3 \\
\hline Bilobectomy & 128 & 4.0 \\
\hline Pneumonectomy & 113 & 3.5 \\
\hline Wedge resection & 98 & 3.1 \\
\hline Exploratory thoracotomy & 65 & 2.0 \\
\hline \multicolumn{3}{|l|}{ Histologic diagnosis } \\
\hline Adenocarcinoma & 2,557 & 80.5 \\
\hline Squamous cell carcinoma & 416 & 13.1 \\
\hline Adenosquamous carcinoma & 89 & 2.8 \\
\hline Large-cell carcinoma & 60 & 1.9 \\
\hline Other types of lung cancer & 55 & 1.7 \\
\hline Perioperative therapy & 967 & 30.4 \\
\hline Neo-adjuvant chemotherapy & 294 & 9.3 \\
\hline Neo-adjuvant targeted therapy & 277 & 8.7 \\
\hline Adjuvant chemotherapy & 729 & 22.9 \\
\hline Adjuvant targeted therapy & 312 & 9.8 \\
\hline Postoperative radiotherapy & 467 & 14.7 \\
\hline
\end{tabular}

in the $8^{\text {th }}$ edition. A total of $1,821(57.3 \%)$ patients were classified into stage N0 (without nodal involvement); 518 (16.3\%) patients were in stage N1 (ipsilateral peribronchial and/or ipsilateral hilar lymph nodes and intrapulmonary nodes); 814 (25.6\%) patients were in stage N2 (with metastasis in ipsilateral mediastinal and/or subcarinal lymph nodes); and $24(0.8 \%)$ were in stage $\mathrm{N} 3$ (patients were metastasis in contralateral mediastinal, contralateral hilar, ipsilateral or contralateral scalene or supraclavicular lymph nodes). Since our data are all from surgical cases, few patients were classified in stage $\mathrm{N} 3$.

Table 4 lists the data of patients after regrouping according to the IASLC-proposed $\mathrm{N}$ subgroups. It shows that: $518(16.3 \%)$ patients in stage N1 were divided to
N1a and N1b with 303 (9.5\%) and 215 (6.8\%) patients, respectively; and $814(25.6 \%)$ patients in stage $\mathrm{N} 2$ were separated into N2a1, N2a2 and N2b with 240 (7.6\%), 279 (8.8\%) and 295 (9.3\%) patients, respectively. No regrouping occurred in N0 and N3, and, thus, they stayed same as in Table 3.

According to our more extensive stratifications: patients in N1 stage (518) were divided into N1a, N1b and N1c, with 303 (9.5\%), $180(5.7 \%)$ and $35(1.1 \%)$ patients in each stage, respectively; patients in $\mathrm{N} 2$ stage were separated into N2a1, N2a2, N2b1, N2b2, and N2c, with 240 (7.6\%), 279 (8.8\%), $40(1.3 \%), 213(6.7 \%)$ and $42(1.3 \%)$ patients in each stage, respectively; and 24 patients in stage N3 were subdivided into $\mathrm{N} 3 \mathrm{a}$ and $\mathrm{N} 3 \mathrm{~b}$, with $8(0.3 \%)$ and $16(0.5 \%)$ patients in each stage, respectively (Table 5).

\section{Survival rates based on the $8^{\text {th }}$ edition of nodal classification system}

The overall survival rate (OS) according to the $8^{\text {th }}$ edition of the $\mathrm{N}$ staging system is summarized in Table 3: stage N0 (75.7\%), state $\mathrm{N} 1$ (60.6\%), stage N2 (33.5\%), and stage N3 (4.2\%). Prognostic significance was found between each adjacent $\mathrm{N}$ classification $(\mathrm{P}<0.001)$. Survival curves are visualized in Figure $1 \mathrm{~A}$.

The survival rates of subgroups based on the IASLCproposed $\mathrm{N}$ subgroup system are shown in Figure $1 \mathrm{~B}$ and summarized in Table 4. Specifically, the survival rates of the N1 and N2 subgroups were: N1a (65.5\%), N1b (50.4\%), N2a1 (46.4\%), N2a2 (36.6\%), and N2b (16.0\%). Prognostic significance was found between each adjacent $\mathrm{N}$ classification $(\mathrm{P}<0.05)$, except between $\mathrm{N} 1 \mathrm{~b}$ and $\mathrm{N} 2 \mathrm{a} 1$ $(\mathrm{P}=0.85)$.

\section{Survival rates based on our proposed further division method}

Survival rates according to our proposed further $\mathrm{N}$ subgroup divisions are shown in Figure $2 A$ and summarized in Table 5. Specifically, as shown in Figure 2B, the survival curves decreased as N1 classification progressed: N1a (65.5\%), N1b (58.8\%), and N1c (5.8\%). Prognostic significance was found between each stage $(\mathrm{P}<0.05)$. In the $\mathrm{N} 2$ group, the survival rate and the survival curves also decreased as the $\mathrm{N}$ classification progressed (Figure 2C): N2a1 (46.4\%), N2a2 (36.6\%), N2b1 (20.4\%), N2b2 (18.6\%), and N2c (0.0\%). Prognostic significance was found between N2a1 and N2a2 (P=0.001), and N2b2 and N2c (P=0.004); 
Table 3 Survival analysis of patients classified by the 8th edition nodal staging system

\begin{tabular}{|c|c|c|c|c|c|}
\hline $\mathrm{N}$-descriptor & Number (percentage) & Five-year survival rate & Median survival (years) & $\mathrm{HR}(95 \% \mathrm{Cl})$ & $P$ value \\
\hline N1 & $518(16.3)$ & $60.6 \%$ & 4.83 & $0.483(0.417-0.560)$ & $<0.001$ \\
\hline N2 & $814(25.6)$ & $33.5 \%$ & 2.75 & $0.344(0.226-0.523)$ & $<0.001$ \\
\hline N3 & $24(0.8)$ & $4.2 \%$ & 1.50 & - & - \\
\hline
\end{tabular}

Table 4 Survival analysis of patients classified by the 8th edition nodal subgroups

\begin{tabular}{|c|c|c|c|c|c|}
\hline $\mathrm{N}$ - descriptor & Number (percentage) & Five-year survival rate & Median survival (years) & $\mathrm{HR}(95 \% \mathrm{Cl})$ & $P$ value \\
\hline $\mathrm{N} 1 \mathrm{a}$ & $303(9.5)$ & $65.5 \%$ & 5.17 & $0.592(0.464-0.755)$ & $<0.001$ \\
\hline $\mathrm{N} 1 \mathrm{~b}$ & $215(6.8)$ & $50.4 \%$ & 3.33 & $1.024(0.802-1.308)$ & 0.85 \\
\hline N2a1 & $240(7.6)$ & $46.4 \%$ & 4.00 & $0.692(0.556-0.863)$ & 0.001 \\
\hline $\mathrm{N} 2 \mathrm{~b}$ & $295(9.3)$ & $16.0 \%$ & 1.92 & $0.641(0.417-0.984)$ & 0.042 \\
\hline N3 & $24(0.8)$ & $4.2 \%$ & 1.50 & - & - \\
\hline
\end{tabular}

Table 5 Survival analysis of patients classified by our proposed further divisions

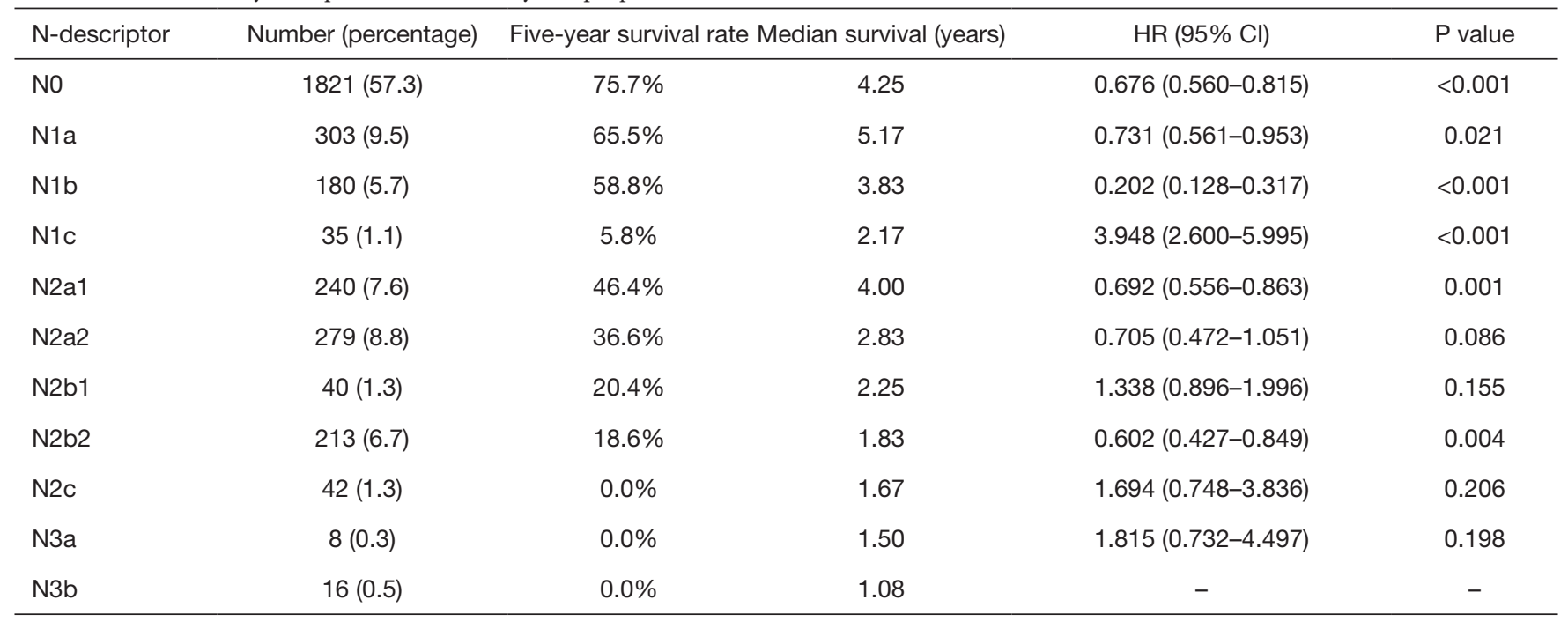

however, there was no significant difference found between stages $\mathrm{N} 2 \mathrm{a} 2$ and $\mathrm{N} 2 \mathrm{~b} 1(\mathrm{P}=0.086)$, nor between $\mathrm{N} 2 \mathrm{~b} 1$ and $\mathrm{N} 2 \mathrm{~b} 2(\mathrm{P}=0.155)$. In the $\mathrm{N} 3$ group (Figure $2 D)$, the survival rates and survival curves decreased as the $\mathrm{N}$ classification progressed, while the overall survival rate of each stage was $0.0 \%$ and prognostic significance was not found between the subgroups $(\mathrm{P}=0.198)$.

\section{Discussion}

The TNM classification system is the most commonly used staging criteria for cancer and is implemented 

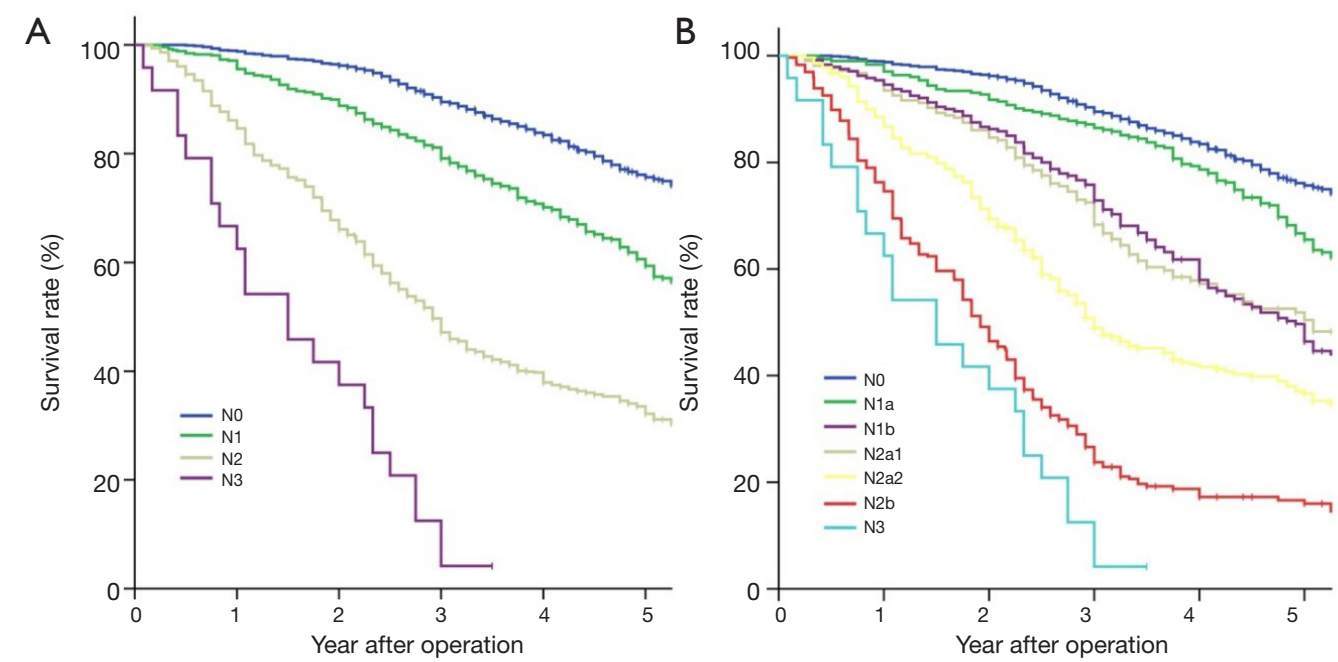

Figure 1 Survival curves of patients according to the $\mathrm{N}$ descriptors in the 8 th edition (A) and the $\mathrm{N}$ subgroups (B) proposed by IASLC with a follow-up duration of five years after surgical resection. Data were censored (+) at the date of the last visit for surviving patients. The survival curves were plotted by Kaplan-Meier method, and a log-rank test was used to for comparisons between curves. IASLC, International Association for the Study of Lung Cancer.

for patients across different countries and ethnicities. However, deficiencies remain in the latest $\left(8^{\text {th }}\right)$ edition of the nodal staging system, notably in relation to the global distribution of the data on which the system is based (5). Countries with high populations, such as India and China, are underrepresented, while others, Japan in particular, are overrepresented. Our study included more than 3,000 NSCLC patients from China, and we found that a subgroup stratification method which takes into account location and the absence versus the presence of skip metastasis is deserving of further studies in future.

The nodal staging system assesses tumor burden in the regional hilar and mediastinal nodes $(2,16)$. In relation to lung cancer, lymph node metastasis is graded in terms of the location of involved lymph nodes regardless of the number of lymph nodes involved (Table 1). The locationbased principle of lung cancer has been widely accepted due to its prognostic ability, and the ease with which lymph node locations can be determined via CT. Our study also confirmed that patients could be prognostically classified to $\mathrm{N} 0$ to $\mathrm{N} 3$ according to the location of involved lymph node stations. In short, the higher the number after $\mathrm{N}$, the worse the prognosis and the lower the survival rate (Figure 1A, Table 3).

However, the tumor burden at regional lymph nodes is not reflected at all in the location-based categorization, and an increasing number of studies have shown that even in the same nodal station, prognosis is different for many patients (17-20). The possibility of lung cancer categorization according to the number of affected lymph nodes as opposed to their location has been studied in the past. Wei (19) and Saji (20) et al. compared the two categorizations, according to the location and number of metastatic lymph nodes and showed that the number-based staging method is a better prognostic determinant than the location-based classification. Our data demonstrated that patients with N2 metastasis at a single lymph node station without hilar involvement (N2a1) had a similar survival rate compared to those with $\mathrm{N} 1$ metastasis at multiple stations (N1b). Asamura et al. (5) also found that the patients with N2a1 had better a better survival rate than those with N1b. Thus, location-based classification could not fully reflect tumor burden. However, on the other hand, there are problems with the practical application of number-based categorization (19). For example, it is quite challenging to determine the number of nodes before treatment by lowresolution imaging diagnosis $(16,21)$, and on a positron emission tomographic image, metastatic nodes are not separated for accurate counting. This difficulty in counting the number of metastatic nodes affects the staging of patients.

In our study, we pioneered a method for distinguishing lymph nodes. Clinically, we noticed that the prognosis of patients with all lymph nodes in the same station was 

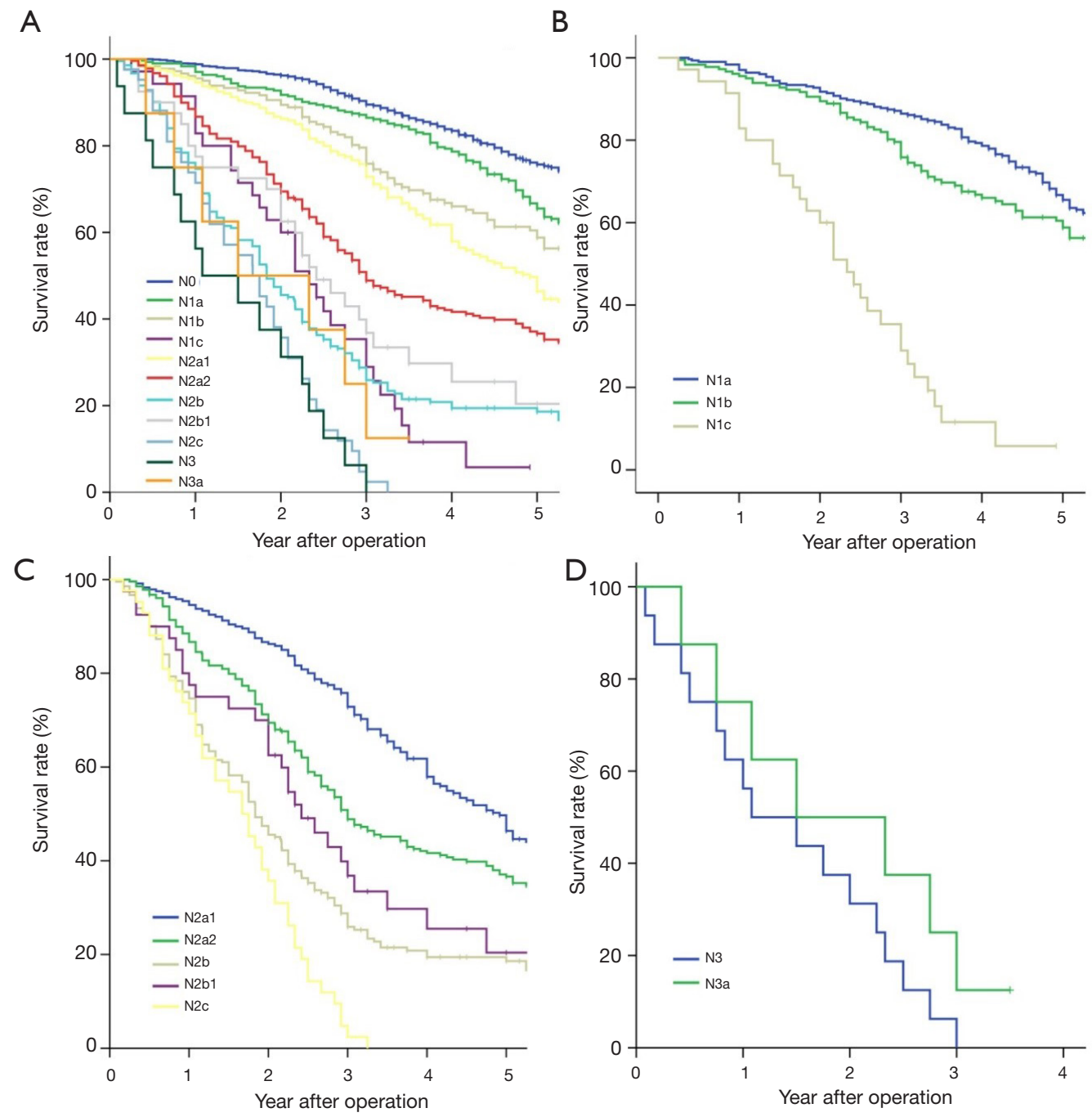

Figure 2 Survival curves of patients according to our proposed further division method with a follow-up duration of five years after surgical resection: (A) all groups, (B) N1 subgroup, (C) N2 subgroup, (D) N3 subgroup. Data were censored (+) at the date of the last visit for surviving patients. The survival curves were plotted by Kaplan-Meier method, and a log-rank test was used to for comparisons between curves.

different from those with a single node in the same station, and multiple lymph nodes were invaded. The prognosis of patients with all lymph nodes in the same station was significantly worse. Our findings also confirm that our proposed lymph node staging method is rational (Table 5, Figure 2), but the staging of this method is too complicated. The current lymph node staging program is divided into 4 stations: N0, N1, N2, and N3; the IALSC-recommended staging plan is divided into 7 stations N0, N1a, N1b, N2a1, $\mathrm{N} 2 \mathrm{a} 2, \mathrm{~N} 2 \mathrm{~b}$, and $\mathrm{N} 3$; and our proposed staging system is divided into 11 stations: N0, N1a, N1b, N1c, N2a1,
$\mathrm{N} 2 \mathrm{a} 2, \mathrm{~N} 2 \mathrm{~b} 1, \mathrm{~N} 2 \mathrm{~b} 2, \mathrm{~N} 2 \mathrm{c}, \mathrm{N} 3 \mathrm{a}$, and N3b. We recommend that the staging scheme recommended by the IALSC is implemented with the addition of the N1b and N2a1 subgroups (which are divided into 6 stations: N0, N1a, N1b/N2a1, N2a2, N2b, and N3). This would allow the difference in the survival rates of different $\mathrm{N}$ stages based on both location and number of lymph nodes to be reflected using staging that is not too complicated implement .

Lastly, future revisions should standardize the method used to evaluate harvested lymph nodes. It has been shown that the incomplete retrieval of lymph nodes from resected 
specimens significantly affects nodal staging (22). According to the TNM system, at least six lymph nodes should be removed, three from $\mathrm{N} 1$ and three from $\mathrm{N} 2$ stations. This is the minimum requirement for a diagnosis of $\mathrm{N} 0$ station when lymph nodes are negative (23). Future staging systems should provide guidelines or suggestions regarding a standardized method for evaluating dissected/removed lymph nodes, as well as a formula for reporting. In addition, future revisions should be based on an internationally extensive data set, and global collaboration for the collection of well-balanced data from all over the world must be addressed for future revisions.

\section{Conclusions}

Our results showed the location-based $\mathrm{N}$ descriptors of lung cancer in the $8^{\text {th }}$ edition of the TNM classification systems to have good outcomes and that patients could be classified in different groups with significantly different survival rates. The IASLC-proposed N subgroup classifiers, which involve the combination of location and absence or presence of skip metastasis could separate the majority patients clearly apart from those in the N1b and N2a1 groups. Patients classified according to our proposed further division method showed different survival rates; however, our system is too complicated and would be difficult to implement. Thus, in conclusion, we recommend the IASLC subgroup classification method with the inclusion of the N1b and N2a1 groups.

\section{Acknowledgments}

None.

\section{Footnote}

Conflicts of Interest: The authors have no conflicts of interest to declare.

Ethical Statement: The authors are accountable for all aspects of the work in ensuring that questions related to the accuracy or integrity of any part of the work are appropriately investigated and resolved. This retrospective study was approved by the Institutional Review Board of Peking University Cancer Hospital (No. 2018YJZ51), and the requirement for patients' consent was waived.

\section{References}

1. Bray F, Ferlay J, Soerjomataram I, et al. Global cancer statistics 2018: GLOBOCAN estimates of incidence and mortality worldwide for 36 cancers in 185 countries. CA Cancer J Clin 2018;68:394-424.

2. de Groot PM, Wu CC, Carter BW, et al. The epidemiology of lung cancer. Transl Lung Cancer Res 2018;7:220-33.

3. Li S, Ma Y, Xiong Y, Zhang P, et al. Five tumor-associated autoantibodies expression levels in serum predict lung cancer and associate with poor outcome. Transl Cancer Res 2019;8:1364-73.

4. Ferretti S, Patriarca S, Carbone A, et al. TNM classification of malignant tumours, VII edition 2009. Changes and practical effects on cancer epidemiology. Epidemiol Prev 2010;34:125-8.

5. Asamura H, Chansky K, Crowley J, et al. The International Association for the Study of Lung Cancer Lung Cancer Staging Project: Proposals for the Revision of the N Descriptors in the Forthcoming 8th Edition of the TNM Classification for Lung Cancer. J Thorac Oncol 2015;10:1675-84.

6. Goldstraw P, Chansky K, Crowley J, et al. The IASLC Lung Cancer Staging Project: Proposals for Revision of the TNM Stage Groupings in the Forthcoming (Eighth) Edition of the TNM Classification for Lung Cancer. J Thorac Oncol 2016;11:39-51.

7. Palmero R, Navarro-Martin A, Nadal E. Comment on an external validation of the 8th edition of the TNM classification for lung cancer staging in patients treated with chemoradiation. Ann Transl Med 2019;7:S101.

8. Lim W, Ridge CA, Nicholson AG, et al. The 8(th) lung cancer TNM classification and clinical staging system: review of the changes and clinical implications. Quant Imaging Med Surg 2018;8:709-18.

9. Byrd DR, Greene FL. The Eighth Edition of TNM: Implications for the Surgical Oncologist. Ann Surg Oncol 2018;25:10-2.

10. Patriarca S, Ferretti S, Zanetti R. TNM Classification of malignant tumours - Eighth edition: which news? Epidemiol Prev 2017;41:140-3.

11. Detterbeck FC, Boffa DJ, Kim AW, et al. The Eighth Edition Lung Cancer Stage Classification. Chest 2017;151:193-203.

12. Cao M, Chen W. Epidemiology of lung cancer in China. 
Thorac Cancer 2019;10:3-7.

13. Yang D, Liu Y, Bai C, et al. Epidemiology of lung cancer and lung cancer screening programs in China and the United States. Cancer Lett 2020;468:82-7.

14. Liang W, He J, Shen Y, et al. Impact of Examined Lymph Node Count on Precise Staging and Long-Term Survival of Resected Non-Small-Cell Lung Cancer: A Population Study of the US SEER Database and a Chinese MultiInstitutional Registry. J Clin Oncol 2017;35:1162-70.

15. Li Z, Yu Y, Lu J, et al. Analysis of the T descriptors and other prognosis factors in pathologic stage I non-small cell lung cancer in China. J Thorac Oncol 2009;4:702-9.

16. Weng E, Tran L, Rege S, et al. Accuracy and clinical impact of mediastinal lymph node staging with FDG-PET imaging in potentially resectable lung cancer. Am J Clin Oncol 2000;23:47-52.

17. Keller SM, Vangel MG, Wagner H, et al. Prolonged survival in patients with resected non-small cell lung cancer and single-level N2 disease. J Thorac Cardiovasc Surg 2004;128:130-7.

18. Rami-Porta R. Quantification of regional lymph node

Cite this article as: Wang J, Wu N, Lv C, Yan S, Yang Y. Recommended changes for the 8th edition of the TNM classification for lung cancer-the findings of a single-institution evaluation. Ann Transl Med 2020;8(4):123. doi: 10.21037/ atm.2020.01.129 involvement in lung cancer. Thorax 2011;66:271-2.

19. Wei S, Asamura H, Kawachi R, et al. Which is the better prognostic factor for resected non-small cell lung cancer: the number of metastatic lymph nodes or the currently used nodal stage classification? J Thorac Oncol 2011;6:310-8.

20. Saji H, Tsuboi M, Shimada $Y$, et al. A proposal for combination of total number and anatomical location of involved lymph nodes for nodal classification in non-small cell lung cancer. Chest 2013;143:1618-25.

21. Carvalho P, Baldwin D, Carter R, et al. Accuracy of CT in detecting squamous carcinoma metastases in cervical lymph nodes. Clin Radiol 1991;44:79-81.

22. Ramirez RA, Wang CG, Miller LE, et al. Incomplete intrapulmonary lymph node retrieval after routine pathologic examination of resected lung cancer. J Clin Oncol 2012;30:2823-8.

23. Wohlschläger J, Wittekind C, Theegarten D. [New TNM classification of malignant lung tumours]. Pathologe 2010;31:355-60. 